\title{
THE CONSTRUCTION OF KNOWLEDGE UNDER NEW PARADIGMS
}

The traditional university classroom has changed very little over the past hundred years in relation to teaching and learning methodologies. Every time a technological innovation appears, we attempt to adapt it to our old paradigms. Up until now, all attempts to use the Internet for teaching purposes have somehow reproduced the old traditional classroom.

The Center for the Study of Venoms and Venomous Animals, CEVAP-UNESP, São Paulo, Brazil, has produced e-learning materials for years. Videos, CD-ROMS, and DVD-ROMS on Toxinology are available. These in conjunction with our website www.cevap.org.br have been successfully used in the distance course on Animal Envenoming.

The new technologies are well developed; we now have to focus on pedagogy! We have to find new ways of providing students with rich learning experiences. We must ask ourselves how to innovate and let go of traditional ways.

Brazil, a country of continental size, will only be able to promote equal opportunities by thoroughly embracing the use of these new tools.

CEVAP through its researchers has made full use of these new paradigms.

Last but by no means the least, the Internet will certainly expand giving all of mankind equal access to Knowledge. Any resistance to these new paradigms is useless.

E-learning is here to stay. What is your contribution?

Benedito Barraviera

Editor-in-Chief

Email bbarraviera@laser.com.br

Rui Seabra Ferreira Júnior

Submissions Editor

Email: rseabra@cevap.org.br 